\title{
Integración económica, crisis económicas y ciclos económicos en México
}

\author{
Economic integration, economic crises, and business cycles in Mexico \\ Cuauhtémoc Calderón Villarreal* y Leticia Hernández Bielma*
}

El Colegio de la Frontera Norte, México

Recibido el 5 de enero de 2015; aceptado el 16 de febrero de 2016

Disponible en Internet el 25 de noviembre de 2016

\begin{abstract}
Resumen
En este artículo se analiza la peculiaridad de la dinámica de las fluctuaciones económicas de la economía mexicana en el marco de su integración con Estados Unidos y Canadá, y se demuestra cómo la economía mexicana endogeneizó las crisis macroeconómicas provenientes de Estados Unidos (2001 y 2007) y cómo los ciclos económicos de ambos países se fueron alineando. Con base en la teoría económica heterodoxa de las crisis y los ciclos verificamos la «ley empírica de la dinámica económica» del sistema capitalista mexicano según la lógica de la teoría del acelerador-multiplicador que nos permitió estudiar la dinámica de las fluctuaciones para el período de estudio (1993-2013). Para ello, construimos y estimamos un modelo VAR estacionario y utilizamos las pruebas de causalidad a la Granger y datos trimestrales.

(C) 2016 Universidad Nacional Autónoma de México, Facultad de Contaduría y Administración. Este es un artículo Open Access bajo la licencia CC BY-NC-ND (http://creativecommons.org/licenses/by-nc-nd/4.0/).
\end{abstract}

Códigos JEL: C32; E32; F02

Palabras clave: Integración económica; TLCAN; Crisis; Ciclos económicos; Crecimiento

\section{Abstract}

This article analyzes the peculiarity of the dynamics of economic fluctuations of the Mexican economy, within the framework of its integration with the US and Canada; the article demonstrates how the Mexican economy make endogenous the macroeconomic crises from the USA (2001 and 2007), and how the business cycles of both countries became more aligned to each other. Based on the heterodox economic theory of

\footnotetext{
* Autores para correspondencia.

Correos electrónicos: calderon@colef.mx (C. Calderón Villarreal), leticiah@ colef.mx (L. Hernández Bielma).

La revisión por pares es responsabilidad de la Universidad Nacional Autónoma de México.
} 
crises and cycles, we check the "empirical law of economic dynamics" of the Mexican capitalist system according to the logic of the Multiplier-Accelerator theory that allowed us to study the dynamics of business cycles for the period of the study (1993-2013). To do this, we construct and estimate a stationary VAR model and utilize the Granger causality tests and quarterly data.

(C) 2016 Universidad Nacional Autónoma de México, Facultad de Contaduría y Administración. This is an open access article under the CC BY-NC-ND license (http://creativecommons.org/licenses/by-nc-nd/4.0/).

JEL classification: $\mathrm{C} 32 ; \mathrm{E} 32 ; \mathrm{F} 02$

Keywords: Economic integration; NAFTA; Crisis; Business cycles; Growth

\section{Introducción}

Con la firma del Tratado de Libre Comercio de Norteamérica (TLCAN) se inicia una fase muy importante en la historia de la economía mexicana. Esta fase ha sido ampliamente analizada por su impacto en el comercio, la inversión y el empleo, entre otras variables macroeconómicas importantes. Pero consideramos que es necesario estudiar las implicaciones macroeconómicas de este período de integración económica en términos de la dinámica de los ciclos económicos y su relación con las crisis económicas que se han dado desde 1994 a la fecha, dado que las políticas macroeconómicas de estabilización de corto plazo y la serie de reformas estructurales aplicadas han tendido a modificar la dinámica de los ciclos y el comportamiento de las crisis económicas.

Particularmente en el período del TLCAN, las políticas de gasto público y de control monetario se convirtieron en potentes instrumentos macroeconómicos para ajustar permanentemente la demanda agregada, convirtiéndose en políticas pro-cíclicas. De allí que los rasgos macroeconómicos dominantes del período fueran la desaceleración, el estancamiento económico, la presencia de ciclos económicos más inestables y las crisis macroeconómicas más agudas. En este trabajo analizamos y corroboramos cómo después de la crisis de 1994 la economía mexicana endogeneizó las crisis macroeconómicas provenientes de Estados Unidos (2001 y 2007), y cómo los ciclos económicos de ambos países se fueron alineando como resultado de la integración creciente de la economía mexicana a la estadounidense, configurándose así una etapa más de inestabilidad macroeconómica en la historia económica del país.

Este artículo se compone en los apartados siguientes: en el primero definimos el concepto de ciclo económico y de crisis desde una perspectiva heterodoxa; en el segundo analizamos las principales características macroeconómicas del período, el comportamiento y la morfología de los ciclos y las crisis económicas en México en el período de estudio; en el tercero estudiamos los co-movimientos de los componentes de la oferta y la demanda agregados con respecto al ciclo económico mexicano y su grado de sincronización con respecto al ciclo estadounidense, y en el cuarto exponemos los resultados econométricos del modelo VAR que aplicamos para simular los efectos de los choques aleatorios sobre el ciclo económico mexicano; finalmente, formulamos las conclusiones.

\section{Marco teórico: crisis y ciclos de crecimiento}

Las principales teorías económicas heterodoxas que han estudiado la relación entre las crisis macroeconómicas y los ciclos económicos establecen que los ciclos y las crisis se explican por la dinámica de la acumulación del capital y de la demanda efectiva. De acuerdo con esto, las crisis 
económicas generales están íntimamente ligadas con la dinámica del ciclo económico; las crisis marcan el fin de una fase de expansión y el inicio de otro ciclo ${ }^{1}$. En este sentido, Marx (1965) sostiene que los ciclos económicos modernos son el resultado de una sucesión de estados del sistema capitalista de producción y hacen referencia a la dinámica y a la reproducción del capital social o global como un conjunto finito de capitales individuales cuyos movimientos determinan la dinámica de la economía capitalista en su totalidad ${ }^{2}$. Así, para Marx (1965) las economías capitalistas siguen una dinámica análoga a «los cuerpos celestes [que] una vez lanzados a sus órbitas las siguen por un tiempo indefinido, lo mismo pasa con la producción social, que cuando es lanzada en este movimiento alternativo de expansión y de contracción lo repite por necesidad mecánica. Los efectos devienen causas y los incidentes, primero irregulares y accidentales, afectan cada vez más la periodicidad normal» (Marx, 1965, pp. 1149-1150). La ley que regula en el largo plazo esta dinámica es la de la caída tendencial de la tasa de ganancia. Desde la perspectiva de Marx, las crisis surgen cuando se da un punto de inflexión ${ }^{3}$, esto es, cuando la sobreproducción de mercancías no encuentra una salida en el mercado ${ }^{4}$ : en ese momento termina una fase de expansión del sistema de producción capitalista ${ }^{5}$. De manera que la plétora de capitales individuales producidos bajo la forma de capital mercantil que no logró venderse da lugar a una crisis general $\left(\mathrm{M}_{\mathrm{kt}}{ }^{\prime}>\mathrm{D}_{\mathrm{kt}}{ }^{\prime}\right)$ bajo la forma de una crisis de demanda efectiva con el desempleo correspondiente. Con lo cual culmina toda una fase de optimismo en el mercado financiero (D-D') ${ }^{6}$. Después de la crisis se abre un período de contracción económica, de destrucción y de aparición de nuevos capitales, individuales, con lo cual se prepara el inicio de una nueva fase de expansión correspondiente a un nuevo ciclo económico. En cada crisis se da una destrucción y fusión masiva de capitales individuales (concentración y centralización de capitales), en particular el capital financiero o ficticio se desvaloriza $\left(\mathrm{D}_{\mathrm{kt}}\right.$ ' $>\mathrm{D}_{\mathrm{kt}}$ ) . Desde una perspectiva más compleja las crisis aparecen como resultado de la caída súbita de la tasa de ganancia y la presencia de una enorme masa de ganancia que no se puede realizar. Así, los ciclos siempre culminan en una crisis general, que marcaría el fin de un ciclo y el inicio de otro: «En el curso del ciclo los negocios pasan por fases sucesivas de depresión, de animación media, de precipitación y de crisis» (Marx, 1965, pp. 1149-1150). «A pesar de que los períodos de inversión del capital difieren unos de otros, la crisis constituye el punto de partida de nuevas inversiones, ella constituye una nueva base material para el próximo ciclo de rotaciones del capital» (Marx, 1965, p. 614). Este mismo autor plantea que los ciclos de tipo Juglar ${ }^{7}$ tienen una duración aproximada de 10 años, pero esta cifra no es constante, ya que su duración depende del progreso técnico (Marx, 1965, pp. 1149-1150) que reduce el tiempo de duración del capital fijo y con ello la temporalidad del ciclo. Así, el progreso técnico es un factor que tienden a reducir la duración del ciclo (Marx, 1965, p. 614).

En la misma perspectiva teórica, Rudolf Hilferding (1971) señala que existe una ley empírica de la dinámica del sistema capitalista según la cual la producción capitalista está comprometida

\footnotetext{
1 «[...] los ciclos siempre culminan en una crisis general, fin de un ciclo e inicio de otro» (Marx, 1965, pp. 1149-1150).

2 De modo que «los ciclos industriales modernos emergen con el capitalismo y su expansión: expansión de la industria, expansión del comercio exterior sobre el comercio interno, expansión del mercado universal que se anexa sucesivamente amplios territorios del nuevo mundo, Asia, Australia, África» (Marx, 1965, pp. 1149-1150).

${ }^{3} \mathrm{Mkt}^{\prime}>$ Dkt' $(\mathrm{k}=1 \ldots \mathrm{n}$ capitalistas individuales y $\mathrm{t}=$ tiempo $)$ que tiene su origen en la no realización de los bienes necesarios y suntuarios producidos $(\mathrm{M})$ en el sector II, donde IIc $>\mathrm{I}(\mathrm{v}+\mathrm{pv})$, así como en los bienes de capital producidos en el período.

${ }^{4}$ Sobreproducción de capital mercantil que no se realiza al curso normal del ciclo capitalista $\mathrm{M}_{\mathrm{kt}}$ ' $=\mathrm{D}_{\mathrm{kt}}$ '.

${ }^{5}$ Definido por el ciclo del capital social como sigue: $\mathrm{D}_{\mathrm{kt}}-\mathrm{M}_{\mathrm{kt}}<{ }_{\mathrm{MPT}}$...P. . . M $\mathrm{kt}_{\mathrm{kt}}$ ' $>\mathrm{D}_{\mathrm{kt}}$ '.

6 Que permitió la afluencia masiva de los capitales individuales hacia sectores económicos específicos.

7 Juglar (1889).
} 
en un círculo de prosperidad y depresión en donde las crisis generales resultan del paso de una fase a otra (Hilferding, 1971, p. 270), «[...] en un momento dado de la prosperidad surge un estancamiento en una serie de ramas de la producción: en consecuencia, disminuyen los precios. El estancamiento y la reducción de los precios se extienden; la producción se limita y este estado de cosas dura más o menos tiempo. Los precios y los beneficios son bajos y poco a poco empieza a ampliarse la producción, suben los precios y aumenta el beneficio. El volumen de la producción es mayor que nunca hasta que vuelve a variar la situación. La repetición periódica de este proceso plantea la cuestión de sus causas, que tienen que averiguarse mediante el análisis del mecanismo de la producción capitalista» (Hilferding, 1971, p. 270). Otro factor que provoca el estallido de las crisis es el desequilibrio que se desencadena entre las ramas productivas del sistema de producción capitalista debido al carácter anárquico de la producción capitalista y la falta de proporcionalidad entre ellas que se expresa en la perturbación de la ley del precio.

Joseph Schumpeter (1935), a su vez, considera que la dinámica del desenvolvimiento capitalista no es uniforme ni lineal, sino que es fluctuante, ya que mantiene ascensos y descensos típicos. Estos ascensos y descensos se caracterizan por la presencia de puntos de inflexión o crisis que marcan la ruptura entre ambas fases. Para Schumpeter (1935), las crisis son el pasaje de la prosperidad a la depresión y dan pie a la aparición de eventos anormales (pánicos, quiebras, rupturas, etc.). Para Schumpeter (1935), la única causa de la depresión es la prosperidad, la depresión es la reacción del sistema económico capitalista frente al auge económico que le precedió.

Por su parte, la explicación de Keynes (2005) sobre las crisis generales y el ciclo económico se sitúa en la perspectiva de la demanda efectiva $\left(\mathrm{M}_{\mathrm{kt}}\right.$ ' $>\mathrm{D}_{\mathrm{kt}}$ '); según él, las crisis macroeconómicas son el resultado de la caída repentina de la eficacia marginal del capital y representan el cambio repentino y violento de la situación macroeconómica en un país; para Keynes (2005), en los últimos estadios del auge económico las expectativas referentes a los rendimientos futuros son demasiado optimistas y se da una abundancia creciente de los bienes de capital, un alza de sus costos de producción y de las tasa de interés; por ello, las crisis macroeconómicas aparecen al final de una fase ascendente de prosperidad y marcan el inicio de una fase de recesión y depresión económicas. Keynes (2005) considera, así, que en los últimos estadios del auge económico las expectativas referentes a los rendimientos futuros son demasiado optimistas. Y los cursos bursátiles caen de manera repentina y catastrófica cuando la desilusión se abate sobre un mercado demasiado sobrevaluado u optimista, por lo que sobreviene el pánico y las quiebras, así como una destrucción masiva de capital financiero $\left(\mathrm{D}_{\mathrm{kt}}{ }^{\prime}>\mathrm{D}_{\mathrm{kt}} \gg\right)$, situación que también describe Marx.

Podemos observar que para Marx, Hilferding, Schumpeter y Keynes las crisis macroeconómicas son momentos necesarios de la dinámica económica capitalista, representada por los ciclos económicos, por lo que tienen un carácter endógeno y están determinadas por la inversión y la acumulación del capital.

\section{Comportamiento macroeconómico, crisis y morfología de los ciclos en la economía mexicana}

Desde la perspectiva de Marx (1965), Hilferding (1971), Schumpeter (1935) y Keynes (2005), los ciclos y las crisis están estrechamente asociados. De acuerdo con estos autores, existe una «ley empírica de la dinámica económica» del sistema capitalista según la cual el desenvolvimiento del sistema económico sigue una trayectoria empírica cíclica irregular, con fases de ascenso-crisisdescenso, cuya existencia verificaremos empíricamente para el caso de México.

Durante el período 1994-2013 se aplicaron las reformas estructurales de primera y segunda generación derivadas del Consenso de Washington, y a partir de 1994 predominó un régimen de 
Tabla 1

Comportamiento macroeconómico de la economía mexicana: 1993-2012

\begin{tabular}{|c|c|c|c|c|c|c|c|c|}
\hline México & $\begin{array}{l}\mathrm{X}^{\mathrm{a}} \\
\% \mathrm{PIB}\end{array}$ & $\begin{array}{l}\mathrm{M}^{\mathrm{b}} \\
\% \mathrm{PIB}\end{array}$ & $\begin{array}{l}\text { F B de C, } \\
\% \text { PIB }\end{array}$ & $\Delta \mathrm{PIB}$ & $\begin{array}{l}\Delta \text { PIB } \\
\text { per-cápita }^{c}\end{array}$ & $\begin{array}{l}\text { Desempleo, } \\
\text { total }(\%)\end{array}$ & Inflación & $\begin{array}{l}\text { Tipo de } \\
\text { cambio real }\end{array}$ \\
\hline 1993 & 15 & 19.2 & 21 & 2 & $-0.3 \%$ & 3.2 & 9.8 & 5.6 \\
\hline 1994 & 17 & 21.6 & 22 & 4.5 & $3.1 \%$ & 4.2 & 7.0 & 5.8 \\
\hline 1995 & 30 & 27.7 & 20 & -6.2 & $-10.4 \%$ & 6.9 & 34.8 & 8.4 \\
\hline 1996 & 32 & 30 & 23 & 5.1 & $3.9 \%$ & 5.2 & 35.3 & 7.6 \\
\hline 1997 & 30 & 30.4 & 26 & 6.8 & $6.1 \%$ & 4.1 & 20.8 & 6.7 \\
\hline 1998 & 31 & 32.8 & 24 & 4.9 & $3.8 \%$ & 3.6 & 15.9 & 6.8 \\
\hline 1999 & 31 & 32.4 & 24 & 3.9 & $2.7 \%$ & 2.5 & 16.7 & 6.2 \\
\hline 2000 & 31 & 32.9 & 24 & 6.6 & $5.8 \%$ & 2.6 & 9.5 & 5.8 \\
\hline 2001 & 28 & 29.8 & 21 & -0.2 & $-1.6 \%$ & 2.5 & 6.4 & 5.6 \\
\hline 2002 & 27 & 28.6 & 21 & 0.8 & $-0.5 \%$ & 2.9 & 5.0 & 5.6 \\
\hline 2003 & 25 & 26.8 & 23 & 1.4 & $-0.8 \%$ & 3 & 4.6 & 6.1 \\
\hline 2004 & 27 & 28.4 & 25 & 4.1 & $3.1 \%$ & 3.7 & 4.7 & 6.2 \\
\hline 2005 & 27 & 28.6 & 24 & 3.2 & $2.2 \%$ & 3.5 & 4.0 & 6.0 \\
\hline 2006 & 28 & 29.2 & 26 & 5.2 & $4.0 \%$ & 3.2 & 3.6 & 6.0 \\
\hline 2007 & 28 & 29.5 & 26 & 3.3 & $2.2 \%$ & 3.4 & 4.0 & 5.9 \\
\hline 2008 & 28 & 30.3 & 27 & 1.2 & $0.1 \%$ & 3.5 & 5.1 & 5.9 \\
\hline 2009 & 28 & 29.1 & 24 & -6 & $-7.7 \%$ & 5.2 & 5.3 & 6.8 \\
\hline 2010 & 30 & 31.6 & 24 & 5.3 & $4.5 \%$ & 5.2 & 4.2 & 6.2 \\
\hline 2011 & 32 & 32.9 & 25 & 3.9 & & 5.3 & 3.4 & 6.1 \\
\hline 2012 & 34 & 35.9 & 25 & 3.9 & & & 4.1 & 6.4 \\
\hline
\end{tabular}

${ }^{\text {a }}$ Exportaciones de bienes y servicios.

b Importaciones de bienes y servicios.

c PIB per cápita, medido en términos de valores de PPA a precios constantes del 2005.

Fuente: INEGI.

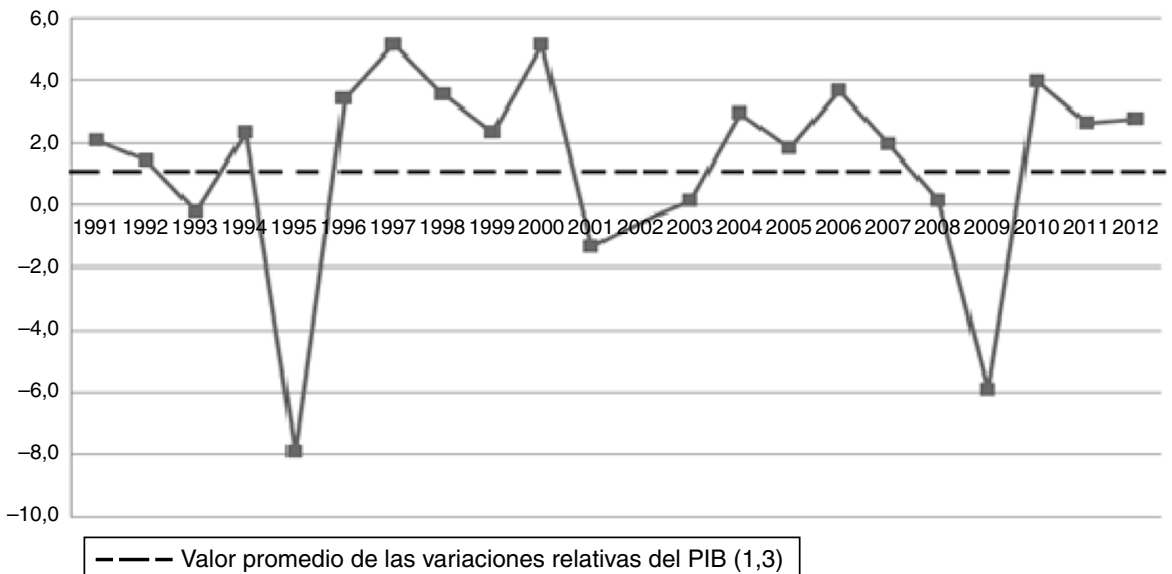

Figura 1. México: Variaciones relativas del PIB per cápita (dólares a precios de 2009).

Fuente: INEGI.

tipo de cambio flexible. El desempleo fue del 3.8\% en promedio, el PIB creció a una tasa promedio del 2.6\%, la participación en promedio de las importaciones sobre el PIB fue del 29.39\%, la de las exportaciones fue del $27.95 \%$ y la de las inversiones, del 23\%. El PIB per cápita de la economía mexicana creció a una tasa promedio del 1.3\% (tabla 1, fig. 1). Dado que este indicador creció por 
debajo del 2.4\%, de acuerdo con la regla de Hausmann se le puede catalogar como una economía estancada.

Otro rasgo macroeconómico característico es que durante todo el período prevaleció una tasa de inflación baja; esta fue de un dígito debido a que el gobierno mantuvo una política monetaria restrictiva de control inflacionario utilizando políticas monetarias y fiscales restrictivas (tabla 1 y fig. 1). La crisis de 1994 demostró que era imposible mantener estable el tipo de cambio, la política Pegged Exchange Rates ${ }^{8}$ para controlar la inflación basada en el tipo de cambio como ancla nominal y aplicada desde 1988 fracasó, por lo que en 1999 se adoptó la estrategia de una política monetaria de tipo inflación objetivo (Inflation Targeting [IT]), con lo cual se pensaba lograr un doble objetivo: la reducción en el nivel y la variabilidad de la inflación, y una alta estabilidad del output. Sin embargo, esta estrategia demostró tanto en México como otros en países su incapacidad para estabilizar simultáneamente el output y la inflación, y lograr simultáneamente bajas tasas de desempleo o altas tasas de crecimiento económico (Brito y Brianne, 2010). Esta política monetaria (IT) favoreció también la apreciación del tipo de cambio real.

Después de la instrumentación en México de las reformas institucionales que condujeron a la autonomía del Banco Central y a la aplicación de una política monetaria basada en Inflation Targeting (IT), se aplicó un régimen monetario de tipo Inflation Targeting Lite (LITE-IT) ${ }^{9}$ (Carare y Stone, 2003).

Esta política monetaria, aunada a una política fiscal restrictiva, reforzó el lento crecimiento de la economía (fig. 1) y redujo la inflación a un dígito.

De esta manera, la aplicación de estas políticas macroeconómicas indujo la restricción de la demanda agregada y la apreciación del tipo de cambio. Por otra parte, la apreciación del tipo de cambio, al favorecer la importación de insumos y de bienes a un costo inferior, contribuyó a la desestructuración de las capacidades productivas de la economía mexicana, lo que condujo a su desaceleración ${ }^{10}$.

Durante todo el período de vigencia del TLCAN los objetivos centrales de la política fiscal han sido mantener un presupuesto equilibrado y una demanda agregada ajustada, aun en períodos macroeconómicos sin inflación; por ello, el gasto público, lejos de convertirse en un instrumento de política anticíclica, devino en un instrumento procíclico ${ }^{11}$ que ha tendido a acentuar los efectos de las crisis macroeconómicas. La dinámica de los ciclos económicos se ha hecho más inestable,

\footnotetext{
${ }^{8} \mathrm{El}$ problema macroeconómico fundamental en las décadas de los setenta, ochenta y noventa fue la inflación, por lo que el gobierno desde 1982 ha instrumentado diversas estrategias para combatirla; así, primero se puso en marcha una política ortodoxa de ajuste que llevó a una contracción y recorte del gasto público que pasó del 36 al $25 \%$ del PIB. Entre 1988-1994 se aplicó un programa heterodoxo anti-inflacionario integrado por dos componentes: un apartado ortodoxo de disciplina presupuestal y un apartado heterodoxo de política coordinada que buscaba la coordinación de los ingresos con base en acuerdos tripartitos (los sindicatos, los empresarios y el gobierno). Las políticas aplicadas tuvieron éxito en reducir la inflación de manera importante (a partir de junio de 1993 la inflación quedó por debajo del 10\%), pero no han logrado impulsar el crecimiento y el desarrollo económico. Hasta la fecha ha quedado pendiente en la agenda de los gobiernos el tema del crecimiento sostenido de la economía (Calderón et al., 2012a).

${ }^{9}$ Con bajos niveles de credibilidad y claridad, y alta flexibilidad para lograr otros objetivos, como las reformas estructurales (Carare y Stone, 2003).

${ }^{10}$ Principalmente las importaciones de insumos productivos y la ausencia de una política industrial, constructora de capacidades productivas, inhibieron el efecto de acelerador por lado de la oferta. En países en vías desarrollo aún son necesarias políticas de fomento industrial, generadoras de capacidades productivas que contribuyen a incrementar el potencial económico para el desarrollo y crecimiento económicos.

${ }^{11}$ La economía mexicana se encuentra en un contexto de estancamiento económico y equilibrio de subempleo, por lo que se necesita la aplicación de una política fiscal activa para reactivarla en el corto plazo y no comprometer el crecimiento.
} 
Tabla 2

Los ciclos económicos de crecimiento en la era del TLCAN

\begin{tabular}{|c|c|c|c|c|c|c|c|c|c|}
\hline \multicolumn{4}{|c|}{ Ascenso } & \multicolumn{4}{|c|}{ Descenso } & \multirow[t]{2}{*}{ Aceleración } & \multirow[t]{2}{*}{ Contracción } \\
\hline $\begin{array}{l}\text { Valle } \\
\text { inicial }\end{array}$ & Pico & Duración & Amplitud & Pico & $\begin{array}{l}\text { Valle } \\
\text { final }\end{array}$ & Duración & Amplitud & & \\
\hline- & 1994.4 & - & - & 1994.4 & 1995.2 & 9 meses & 0.7100 & 0.27 & -0.44 \\
\hline 1995.2 & 2000.3 & $\begin{array}{l}5 \text { años } \\
6 \text { meses }\end{array}$ & 0.6500 & 2000.3 & 2003.3 & $\begin{array}{l}3 \text { años } \\
3 \text { meses }\end{array}$ & 0.4508 & 0.21 & -0.176 \\
\hline 2002.1 & 2007.4 & 6 años & 0.3623 & 2007.4 & 2009.2 & $\begin{array}{l}1 \text { año } \\
5 \text { meses }\end{array}$ & 0.4508 & 0.1871 & -0.2637 \\
\hline 2009.2 & 2012.2 & $\begin{array}{l}3 \text { años } \\
2 \text { meses }\end{array}$ & 0.3663 & 2012.2 & 2013.3 & $\begin{array}{l}1 \text { año } \\
6 \text { meses }\end{array}$ & 0.1196 & 0.1031 & -0.0165 \\
\hline
\end{tabular}

Fuente: INEGI. Elaboración propia en base al INEGI.

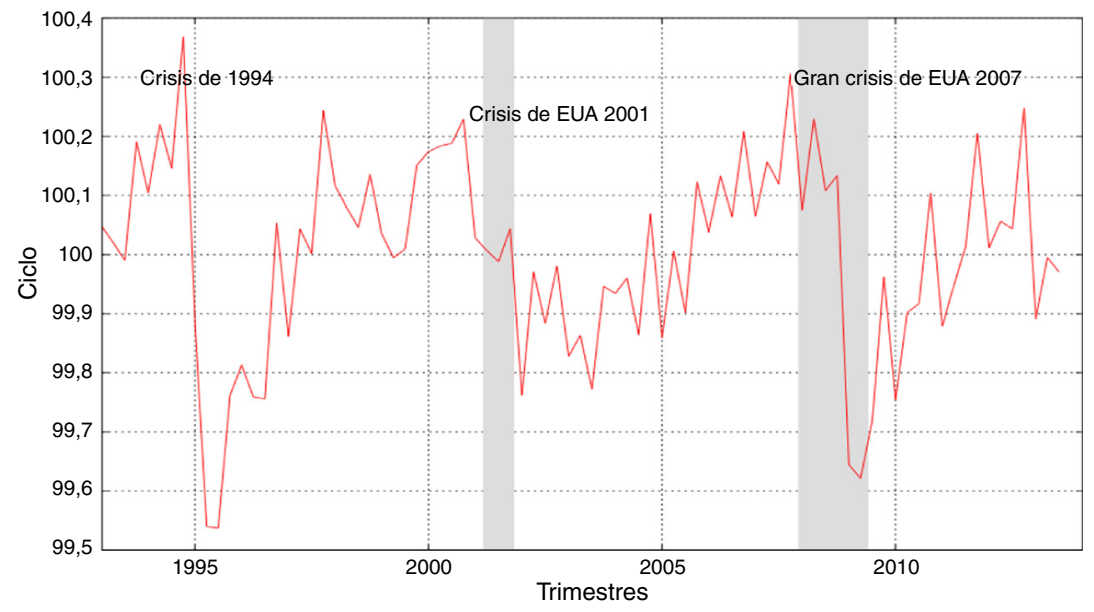

Figura 2. Ciclos de crecimiento en la era del TLCAN.

Fuente: INEGI y National Bureau of Economic Research (NBER).

la recuperación ha sido más débil y se han contraído las fases de expansión de los ciclos por encima del PIB potencial, con lo cual se acentúa la desaceleración de la economía.

Analizaremos ahora, para el caso de México durante el período 1993.1 y 2013.3, la «ley empírica de la dinámica económica», definida por Hilferding; estudiaremos los ciclos de crecimiento que definimos como los ascensos y descensos relativos del PIB con respecto a su tendencia.

Siguiendo esta metodología, se identifican una serie de ciclos de crecimiento de la economía mexicana para el período de estudio 1993.1 y 2013.3 (fig. 2 y tabla 2) que en su conjunto perfilan la trayectoria de su dinámica. Se observa que las fases de estos ciclos de crecimiento del PIB fluctúan alrededor de la línea de tendencia o PIB potencial que viene representada por la línea horizontal de ordenada 100. En la figura 2 se muestra el comportamiento de los ciclos económicos de la economía mexicana, y lo primero que se constata es que no son iguales, y que cada uno varía de manera diferente, tanto en duración como en intensidad o amplitud. Las bandas de color gris de la figura denotan las recesiones de los Estados Unidos de América, que coinciden con las recesiones de la economía mexicana de los años 2001-2002 y 2007-2009. Se observa una tendencia hacia la endogenización de las crisis norteamericanas por parte de la economía mexicana. 
Se constata la presencia de 4 ciclos y 3 crisis macroeconómicas mayores situadas en los picos de los ciclos correspondientes a los años 1994.4, 2000.3 y 2007.4 (véase tabla 2). La crisis de 1994 fue causada fundamentalmente por variables macroeconómicas internas, mientras que las crisis del 2000.3 y del 2007.4 se desencadenaron como consecuencia de las crisis estadounidenses. En la era del TLCAN se observa una tendencia hacia la mayor integración del ciclo económico mexicano con el norteamericano. Además, los ciclos económicos y sus crisis respectivas se han ido haciendo cada vez más volátiles y dependientes de la economía norteamericana. Las crisis macroeconómicas tendieron a alinearse sobre todo con las crisis norteamericanas del 2001-2002 y del 2007-2010 y los ciclos tuvieron una duración promedio de 6.5 años.

De manera que identificamos 4 ciclos durante el período de estudio, cuyas características son las siguientes.

\section{Primer ciclo}

Marcado por la crisis de 1994, llamada la primera crisis de globalización, cuyo origen fue interno, fue resultado de las contradicciones potenciales existentes entre la política antiinflacionaria «heterodoxa» de estabilización, la estrategia de crecimiento orientado hacia las exportaciones y la apertura hacia la globalización del sistema monetario y financiero nacional. La crisis fue consecuencia directa de «la abundancia de entradas de capital externo, resultante de las reformas estructurales y de la coyuntura financiera internacional» (Calderón y Caire, 2012, p. 55), que trajeron consigo una fase de auge para la economía mexicana que engendró una doble dificultad de financiamiento en el ajuste entre el ahorro y la inversión. La crisis financiera del 1994-1995 fue desencadenada por las medidas anti-inflacionarias aplicadas basadas en el tipo de cambio fijo como ancla nominal (Calderón, Caire y Sánchez (2012), la política monetaria de esterilización y un choque político que redujo el optimismo sobre el período. La fase de descenso del ciclo duró 9 meses, la amplitud del descenso fue más profunda (0.71). La fase de desaceleración $(-0.44)$ fue más amplia que la de aceleración $(0.27)$.

\section{Segundo ciclo}

Marcado por la crisis macroeconómica de 2000.3-2001, este ciclo de 8 años se caracteriza por tener una fase de ascenso (0.65) superior a la fase de descenso (0.45), y una fase de aceleración (0.21) superior a la de contracción (-0.176). La expansión estuvo determinada por la expansión que conoció Estados Unidos en los noventa, misma que terminó con la crisis de principios del 2001, momento en que la economía mundial mostró una desaceleración que dio lugar a una contracción severa del comercio internacional. Este deterioro del crecimiento mundial incidió negativamente en el desempeño de la economía mexicana, con sus consecuentes pérdidas en los niveles de inversión y el empleo. En 2002 la economía mexicana se recuperó lentamente.

\section{Tercer ciclo}

Marcado por la gran crisis macroeconómica del 2007.4, este ciclo de 7.5 años se caracteriza por tener una fase de ascenso (0.3623) inferior a la fase de descenso (0.45), y una fase de aceleración (0.1871) inferior a la de contracción $(-0.26)$. La expansión estuvo determinada por la expansión que conoció Estados Unidos después de su recesión de 2001-2002, misma que terminó con la crisis de las subprime, crisis financiera de Estados Unidos de 2007. 
Esta crisis financiera y económica en Estados Unidos ha sido catalogada como la más grave en su género desde la gran depresión del 29 y con un fuerte impacto sobre la economía mundial, de manera que la crisis tendió a revertir las fuerzas económicas expansionistas del mercado mundial, enmarcadas en la ideología dominante del liberalismo y del laissez-faire. La crisis financiera y económica de Estados Unidos fue una crisis general de dimensión global e internacional.

De acuerdo con la dinámica del ciclo económico, la crisis fue la cima o punto de inflexión de las tendencias económicas expansionistas que inaugura la emergencia de una fase de descenso, sobre todo en los países industrializados. La economía estadounidense se contrajo un $0.5 \%$ en el tercer trimestre del 2008, lo que representaría la caída más grande desde 2001. En la economía mexicana, el PIB se contrajo un 6\% entre 2007, 2008 y 2009 y se recuperó en 2010 (tabla 1).

\section{Cuarto ciclo}

Aún no ha terminado, y con una crisis macroeconómica que posiblemente tenga lugar en 2016, es un ciclo de una duración promedio de 8 a 7.5 años. Este ciclo se caracteriza por tener una fase de ascenso (0.3663) y una fase de aceleración (0.1031).

En términos generales se observa que desde la crisis de 1994 la economía mexicana ha sufrido una desaceleración progresiva tendiendo al estancamiento, ligado a la sincronización creciente de la economía mexicana con el ciclo norteamericano en el marco de la llamada globalización. Se observa que la economía endogeneizó de manera progresiva las crisis internacionales y perdió su autonomía y su capacidad de estabilizar su ciclo nacional, endogeneizando el riesgo y la incertidumbre de la economía mundial. Así, las fases de aceleración de los 4 ciclos tendieron a disminuir con $0.27,0.21,0.18$ y 0.10 , respectivamente, con lo cual se observa una tendencia constante hacia la desaceleración de la dinámica de la economía mexicana entre 1993 y 2013. Las crisis del 2000.3 y 2007.4 de Estados Unidos afectaron a la economía mexicana de manera contundente por estar supeditada al ciclo económico estadounidense, sufriendo un impacto muy fuerte sobre su nivel de actividad económica; particularmente, el sector manufacturero fue el más afectado. Además del contagio bursátil derivado de la crisis financiera, la recesión de Estados Unidos redujo los flujos de inversión extranjera y de remesas provenientes de ese país; también las exportaciones y las importaciones cayeron, con lo cual el PIB mexicano sufrió una de las caídas más drásticas de su historia, por lo que el grado de interdependencia de los procesos económicos entre ambos países ha sido cada vez mayor.

\section{Grado de asociaciones de la oferta y demanda agregadas con los ciclos económicos de crecimiento de México}

\section{Metodología utilizada}

A partir de la presencia de los ciclos económicos de crecimiento de la economía mexicana entre 1993.1 y 2013.3, vamos a determinar el grado de asociación o de co-movimiento que existe entre estos ciclos y los componentes de la oferta y demanda agregadas de la economía mexicana (tabla 3). Para proceder a construir las series de los ciclos del PIB real y las variables macroeconómicas asociadas que se presentan en la tabla 3, correspondiente al período de estudio 1993.01-2013.03, primero utilizamos series macroeconómicas desestacionalizadas trimestrales medidas en millones de pesos con base 2008, mismas que procedimos a transformar en logaritmos; 
Tabla 3

Series originales utilizadas

\begin{tabular}{|c|c|c|c|c|}
\hline Series de tiempo de: & Denominación & Unidades & Período & Nota \\
\hline $\begin{array}{l}\text { Producto Interno } \\
\text { Bruto real }\end{array}$ & $\mathrm{PIBr}$ & $\begin{array}{l}\text { Millones de pesos } \\
\text { (año base 2008) }\end{array}$ & 1993:Iq - 2013:IIIq & $\begin{array}{l}\text { Fuente: INEGI, } \\
\text { ajustada } \\
\text { estacionalmente }\end{array}$ \\
\hline Consumo privado & $\mathrm{CP}$ & $\begin{array}{l}\text { Millones de pesos } \\
\text { (año base 2008) }\end{array}$ & 1993:Iq - 2013:IIIq & $\begin{array}{l}\text { Fuente: INEGI, } \\
\text { ajustada } \\
\text { estacionalmente }\end{array}$ \\
\hline Consumo público & $\mathrm{CPU}$ & $\begin{array}{l}\text { Millones de pesos } \\
\text { (año base 2008) }\end{array}$ & 1993:Iq - 2013:IIIq & $\begin{array}{l}\text { Fuente: INEGI, } \\
\text { ajustada } \\
\text { estacionalmente }\end{array}$ \\
\hline Importaciones & M & $\begin{array}{l}\text { Millones de pesos } \\
\text { (año base 2008) }\end{array}$ & 1993:Iq - 2013:IIIq & $\begin{array}{l}\text { Fuente: INEGI, } \\
\text { ajustada } \\
\text { estacionalmente }\end{array}$ \\
\hline Exportaciones & $X$ & $\begin{array}{l}\text { Millones de pesos } \\
\text { (año base 2008) }\end{array}$ & 1993:Iq - 2013:IIIq & $\begin{array}{l}\text { Fuente: INEGI, } \\
\text { ajustada } \\
\text { estacionalmente }\end{array}$ \\
\hline $\begin{array}{l}\text { Formación neta de } \\
\text { capital fijo privado }\end{array}$ & FNCFP & $\begin{array}{l}\text { Millones de pesos } \\
\text { (año base 2008) }\end{array}$ & 1993:Iq - 2013:IIIq & $\begin{array}{l}\text { Fuente: INEGI, } \\
\text { ajustada } \\
\text { estacionalmente }\end{array}$ \\
\hline $\begin{array}{l}\text { Formación bruta de } \\
\text { capital fijo publico }\end{array}$ & FBCFPu & $\begin{array}{l}\text { Millones de pesos } \\
\text { (año base 2008) }\end{array}$ & 1993:Iq - 2013:IIIq & $\begin{array}{l}\text { Fuente: INEGI, } \\
\text { ajustada } \\
\text { estacionalmente }\end{array}$ \\
\hline
\end{tabular}

Tabla 4

Valores promedio de 1993.1 al 2013.3

\begin{tabular}{lllllll}
\hline \multicolumn{2}{l}{ Oferta Agregada } & \multicolumn{5}{c}{ Demanda Agregada } \\
\hline PIB & Importaciones & Exportaciones & Gasto público & Inversión pública & Inversión privada & Consumo privado \\
${ }^{\mathrm{a}} 100$ & 25 & 30 & 12 & 15 & 9 & 65 \\
${ }_{\mathrm{b}}^{\mathrm{a}}$ & 0.0052894 & 0.0033568 & 0.00083432 & 0.0049784 & 0.0017388 & 0.0017839 \\
${ }^{\mathrm{c}} 100$ & 362 & 230 & 57 & 341 & 119 & 122 \\
\hline
\end{tabular}

${ }^{\text {a }}$ Media de las series dividida entre la media del PIB, porcentaje.

b Desviación estándar de la series sin trend dividida entre la media de las series.

c Desviación estándar de las series dividido entre la desviación estándar del PIB.

Fuente: elaboración propia en base a datos del INEGI.

segundo, procedimos a separar la tendencia del ciclo del PIB utilizando el filtro de HodrickPrescott; y tercero, construimos la serie a partir de la definición antes mencionada.

\section{Grado de asociación o de co-movimiento de las componentes de la oferta y la demanda} agregadas con el ciclo mexicano de crecimiento

Antes de examinar la estructura cíclica de los componentes del PIB real es importante estimar la magnitud de la contribución de cada una de las series macroeconómicas a las fluctuaciones económicas. Para ello, en la tabla 4 calculamos una serie de estadísticos relevantes que miden este peso, donde la primera línea nos proporciona la magnitud relativa de los agregados macroeconómicos de la oferta y demanda como porcentaje del PIB. 
Tabla 5

Co-movimientos de las variables y los ciclos

\begin{tabular}{lll}
\hline Agregado & {$[1]$ Correlación con el PIB } & {$[2]$ Volatilidad con respecto al PIB (México) } \\
\hline Consumo privado & $* 0.9502$ & 1.22023 \\
Importaciones & $* 0.8986$ & 3.61807 \\
Exportaciones & $* 0.4112$ & 2.29616 \\
Consumo público & $* 0.3822$ & 0.5707 \\
Formación neta de capital fijo privado & $* 0.2815$ & 1.18936 \\
Formación bruta de capital fijo público & 0.2011 & 3.40527 \\
\hline
\end{tabular}

* Significativas al 5\% para un valor crítico del 0.2146.

Durante el período de análisis, de 1993.1 a 2013.3, observamos que el consumo privado es la variable más relevante, con un $65 \%$, siendo la inversión privada, con el $9 \%$, la que tiene menos peso en la dinámica del PIB.

La segunda línea nos arroja información sobre la intensidad de las fluctuaciones de cada serie con respecto a su valor promedio; es decir, el grado de volatilidad con respecto a su propio promedio; en términos generales es muy baja en todas las series para todo el período de estudio. Sin embargo, se observa que la variable más volátil son las importaciones, y el consumo privado, que es el agregado con mayor peso, es el menos volátil. La tercera línea nos indica el grado de volatilidad de cada una de las variables macroeconómicas con respecto a la desviación estándar del PIB. El gasto público es la variable menos inestable, pero con un peso relativamente bajo en el PIB de solo un 12\%; las variables inestables son las importaciones, con un $25 \%$ de peso en el PIB, y la inversión pública, con solo un $15 \%$ de peso en el PIB. Cabe resaltar que el consumo privado, que fue el que determinó la dinámica del PIB durante el período, fue el que tuvo un nivel de volatilidad más alto, por lo que cualquier variación del consumo privado tendió a magnificar las oscilaciones cíclicas del PIB.

Ahora analizaremos los co-movimientos de las variables con los ciclos de crecimiento, para lo cual estudiaremos el grado de correlación (columna [1], tabla 5) y el nivel de volatilidad (columna [2], tabla 5). Un rasgo importante del período es que todas las variables son procíclicas. El consumo privado fue la variable que — además de tener el mayor peso promedio sobre el PIB durante el período - fue la más correlacionada con el PIB; además, dado que es una variable altamente volátil, fue la que influyó de manera determinante sobre las oscilaciones de los ciclos económicos. En la tabla 5 se muestra el alto grado de correlación que mantiene esta variable con los ciclos del período (0.9502). Asimismo, dado que sus co-movimientos son procíclicos, determinan en un alto nivel las oscilaciones del mismo. Es decir, ceteris paribus, una expansión del consumo privado provoca el ascenso del ciclo y una reducción del mismo trae consigo la contracción del ciclo. En síntesis, durante el período se dio un alto grado de correlación positivo entre consumo privado y los ciclos de crecimiento, por lo que los co-movimientos entre ambas variables son altamente procíclicos. Esta alta correlación se explica en parte por la presencia de los ingresos (remesas, sueldos y salarios), altamente dependiente de la coyuntura, ya que en las fases de expansión aumentan y en las fases de contracción disminuyen.

Las importaciones, variable de la oferta agregada, muestran un alto grado de correlación con los ciclos (0.8986), lo que implicaría que en las fases de expansión económica se incrementan las importaciones de bienes finales e insumos productivos, y en las fases de descenso caen. Esta fuerte correlación se explica por la interdependencia creciente con la economía norteamericana y el peso creciente que tiene el comercio intraindustrial en el sector externo de la economía 
mexicana, derivado de las importaciones de insumos y maquinaria productivos y la consecutiva pérdida de capacidades productivas y desindustrialización de la economía mexicana durante el período. En la fase del TLCAN las transnacionales desarrollan esquemas industriales de producción compartida y de competencia internacional vía la diferenciación de sus productos, implantando en los continentes y el país segmentos de la producción que requieren bajos salarios y mano de obra poco calificada, con lo cual utilizan a México como una plataforma para producir una parte de su producto final que se vende en el mercado estadounidense e internacional. Además, la presencia de un tipo de cambio apreciado ha favorecido el crecimiento del comercio intraindustrial.

Las exportaciones tienen una correlación positiva relativamente baja con el ciclo (0.4112) a pesar de la apertura económica y una volatilidad alta. En parte esto se explica por el hecho de que las exportaciones no se han convertido en el motor de la economía mexicana. Esto se debe sobre todo al peso del comercio intraindustrial, ya que un componente central de las exportaciones orientadas hacia el mercado norteamericano son los bienes armados o maquilados en el territorio nacional. Eso quiere decir que el libre comercio ha favorecido a la competencia monopolística y a las grandes empresas multinacionales. De hecho, el comportamiento del tipo de cambio apreciado ha favorecido a este tipo de estructuras de mercado.

El consumo público mantiene una correlación baja (0.3822) con el ciclo, así como una relación estable con el mismo y es procíclico, reflejo de una política fiscal neoliberal de ajuste macroeconómico que solo busca el control de los precios; política fiscal restrictiva que ha tendido a intensificar la inestabilidad del ciclo como consecuencia de la acentuación de la brecha entre ahorro e inversión. Esto contrasta con lo que sería una política keynesiana del gasto público, que sigue un comportamiento anticíclico, centrada en la reducción del desempleo, con el fin de contrarrestar los efectos de las crisis y las fluctuaciones económicas, y que como componente fundamental de la demanda efectiva compensa la brecha creciente entre ahorro e inversión.

La correlación positiva entre la inversión neta y el ciclo es muy baja (0.2815), lo que nos indicaría que el nivel de asociación entre ambas variables es muy reducido, a pesar de que mantiene una relación positiva y una volatilidad baja, de modo que la inversión privada neta prácticamente no influye sobre el comportamiento del ciclo económico; una explicación es que el efecto multiplicador-acelerador es muy reducido en el marco de una pequeña economía abierta con un bajo nivel del stock capital e inversión doméstica y preponderancia de inversión extranjera; por ello, la inversión privada no cumplió con su papel de equilibrar el mercado de los bienes (I-S o M-M') durante el período.

Finalmente, la inversión pública no tiene ningún grado de asociación con el ciclo, lo que se explica por la política fiscal restrictiva, por la reducción del gasto en inversión pública e infraestructura y por la destrucción de las capacidades productivas de la economía pública que son vitales para el crecimiento y la aceleración económica.

Sincronización del ciclo económico de México y el ciclo norteamericano entre 1993.1 y 2013.3

En este apartado analizamos el grado de sincronización del ciclo mexicano con respecto al ciclo norteamericano. Utilizamos como identificador del ciclo en México a la serie del PIB real a precios de 2008 y como identificador del ciclo en Estados Unidos el GNP desestacionalizado a precios de 2009.

Los ciclos del PIB de México y Estados Unidos están sincronizados (0.536421) (tabla 6). Ello se debe principalmente al alto grado de integración de la economía mexicana con la estadounidense 
Tabla 6

Correlación y volatilidad de los ciclos

\begin{tabular}{llc}
\hline & PIB $_{\text {Mex }}$ & Volatilidad \\
\hline GNP $_{\text {USA }}$ & 0.536421 & 0.082948
\end{tabular}

Fuente: cálculos propios.

a raíz de la firma del TLCAN. Los principales factores explicativos de esto son la preponderancia del comercio intraindustrial entre ambos países, derivado del hecho de que Estados Unidos es el principal socio comercial de México ${ }^{12}$, y que la mayor proporción de la inversión extranjera directa proviene de ese país. Estos factores han fortalecido la interdependencia manufacturera e industrial entre ambas economías, sobre todo con la implantación de las plantas maquiladoras en México. Otro factor ha sido la afluencia migratoria de los mexicanos hacia Estados Unidos, que se dio principalmente en la década de los noventa, lo que ha generado un flujo masivo de remesas hacia nuestro país.

\section{Metodología empírica: especificación del modelo y resultados econométricos del modelo VAR}

Con base en la teoría del modelo acelerador-multiplicador de los ciclos, seleccionamos las variables macroeconómicas que explican el comportamiento del ciclo de crecimiento de la economía mexicana para el período de estudio 1993.1 a 2013.1. En relación con 8 variables macroeconómicas, representadas en la tabla 1, construimos y estimamos un modelo VAR estacionario para analizar la dinámica del ciclo económico. Estudiamos la dinámica de los efectos de corto plazo de los shocks aleatorios en el ciclo, y finalmente realizamos pruebas de causalidad a la Granger.

\section{Selección de las variables macroeconómicas del modelo}

Para evaluar los efectos de corto plazo de los shocks aleatorios sobre el ciclo de crecimiento de la economía construimos un modelo VAR estacionario cuyas variables fueron seleccionadas a partir de la teoría del modelo acelerador-multiplicador. De acuerdo con Harrod (1948), Samuelson (1938) y Kalecki (1935), los desequilibrios de los mercados son los que determinan las fluctuaciones o ciclos. En estos modelos la acumulación del capital y la inversión juegan un papel fundamental, en la medida que la inversión tiene una doble naturaleza: por una parte, es la variable más volátil de la demanda agregada y, por la otra, es una variable esencial para la oferta en una economía cerrada. La dinámica de los desequilibrios engendrados por la acumulación del capital se sintetiza en el modelo del multiplicador-acelerador que proporciona la explicación más importante del ciclo económico. La dinámica del multiplicador-acelerador reposa en el comportamiento de la inversión y los desequilibrios en el mercado de bienes; la inversión está en función de la brecha entre la demanda anticipada y la capacidad de producción disponible y es una variable que ajusta a término el equilibrio del mercado de bienes. Supongamos que existe un período de tiempo de retardo entre la inversión y el incremento del capital, la inversión neta es igual a la brecha entre el stock de capital disponible para el período anticipado $(\mathrm{t}+1)$ y el stock de capital

\footnotetext{
12 México es el tercer socio exportador de Estados Unidos; nuestras exportaciones de bienes finales e hidrocarburos están orientadas hacia esa economía, y existe una dependencia creciente de las importaciones provenientes de Estados Unidos.
} 
disponible para el período (t). Si el coeficiente del capital es constante (v), el capital deseado para el período $(t+1)$ es proporcional a la demanda anticipada $\left(k_{t+1}=v Q_{t+1}\right)$, por lo que la inversión neta puede expresarse como la brecha entre la demanda anticipada y la capacidad disponible, y una proporcionalidad de las variaciones anticipadas de la demanda (modelo acelerador).

$$
I_{t}=v Q_{t+1}-K_{t}=v\left(Q_{t+1}^{*}-Q_{t}^{*}\right)
$$

Extendemos el modelo básico de Samuelson (1938) suponiendo la existencia de una economía pequeña y abierta con el Estado. Este modelo del multiplicador-acelerador es susceptible de engendrar un ciclo conforme a las evoluciones observadas; por ello, partimos de la identidad macroeconómica siguiente:

$$
Q_{t}=A_{t}+C_{t}+I_{t}+G_{t},+X_{t}-M_{t}
$$

La identidad (2) integra: la balanza comercial $\left(\mathrm{X}_{\mathrm{t}}-\mathrm{M}_{\mathrm{t}}\right)$, el gasto gubernamental $\mathrm{G}_{\mathrm{t}}$, el componente autónomo de la demanda $A_{t}$, el consumo privado $C_{t}$, que se ajusta al ingreso con el retardo de un período:

$$
C_{t}=c Q_{t-1}
$$

La inversión privada se ajusta con el retardo de un período a las variaciones de la producción, como sigue ${ }^{13}$ :

$$
I_{t}=v_{1}\left(Q_{t-1}-Q_{t-2}\right)
$$

Las relaciones de comportamiento de las exportaciones están determinadas por el comportamiento del ingreso externo de una gran economía $\left(\mathrm{Q}^{*} \mathrm{t}-1\right)$ :

$$
X_{t}=x Q_{t-1}^{*}
$$

Las importaciones que van a estar determinadas por las fluctuaciones del PIB doméstico:

$$
M_{t}=m Q_{t-1}
$$

El gasto gubernamental se va a definir como sigue:

$$
G_{t}=G_{0}
$$

Aunada a la inversión gubernamental:

$$
I_{t}^{G}=v_{2}\left(Q_{t-1}-Q_{t-2}\right)
$$

Por lo que inversión total va estar definida por la suma de la inversión gubernamental y privada:

$$
I_{t}=I_{t}^{G}+I_{t}^{P}
$$

Resolviendo el modelo tendríamos una forma autorregresiva de segundo orden de la forma siguiente:

$$
Q_{t}=\left(\left(v_{1}+v_{2}\right)\left(Q_{t-1}-Q_{t-2}\right)\right)+\left((c-m) Q_{t-1}+x Q_{t-1}^{*}+A_{t}+G_{t}\right.
$$

\footnotetext{
13 Tenemos otro modelo diferente del ciclo, de tipo acelerador-multiplicador, desarrollado por Kalecki (1935), según el cual la inversión depende de la brecha entre las ganancias y el valor del capital acumulado en una economía cerrada. $\mathrm{I}_{\mathrm{t}}=\mathrm{a} \Pi^{*}{ }_{\mathrm{t}+1}-\mathrm{bK}_{\mathrm{t}}$.
} 
De acuerdo con este modelo (10), los coeficientes de capital $\mathrm{v}_{1}$ privado $\mathrm{y}_{2}$ gubernamental determinan la magnitud de las oscilaciones y propenden a impulsar la expansión de la economía, mientras que las importaciones tienen el efecto contrario $\mathrm{m}<0$ y el $\mathrm{c}>0$ a tener un efecto expansivo derivado del efecto multiplicador junto con las exportaciones $\mathrm{x}>0$.

\section{Variables, datos, especificación empírica del modelo VAR}

Se estima un modelo econométrico VAR estacionario, y utilizamos la teoría del aceleradormultiplicador para seleccionar las variables endógenas que lo integran. Esta técnica econométrica nos va a permitir evaluar los impactos derivados de los shocks aleatorios generados por los cambios de estas variables macroeconómicas (el consumo privado, la inversión pública y la privada, el producto neto de Estados Unidos, las importaciones y las exportaciones) sobre el ciclo económico para el período de análisis (1993.1-2013.3). Además, realizamos un análisis de causalidad de tipo Granger (1969) para determinar cuáles de las variables consideradas causan en el sentido de Granger al ciclo. De este modo, en su conjunto vamos a validar la explicación teórica que ofrece del ciclo el modelo acelerador-multiplicador y definir su grado de validez para el caso mexicano en el período de 1993.1 a 2013.3. Las variables seleccionadas para la estimación del modelo VAR estacionario están representadas en la tabla 1, tienen una frecuencia trimestral y abarcan el período de 1993.1 a 2013.3. Todas las series macroeconómicas están desestacionalizadas y están medidas en pesos del 2008. Todas fueron transformadas en logaritmos y se les eliminó la tendencia a partir de una descomposición de las series, utilizando el filtro Hodrick-Prescott.

Por lo general los vectores autorregresivos (VAR (p)) se utilizan para predecir el comportamiento de sistemas de series temporales que están interrelacionadas. También se utilizan para analizar la dinámica generada por el impacto de un shock aleatorio en alguna de las variables del sistema de variables (llamadas funciones de impulso-respuesta [IRF]). El enfoque VAR evita la necesidad de hacer la distinción a priori entre variables exógenas y endógenas a partir de una teoría predeterminada, esto se logra al tratar individualmente a cada variable endógena del sistema como una variable determinada por los valores pasados de todas las variables endógenas del sistema mismo. El modelo VAR (p) se formula matemáticamente de la siguiente manera:

$$
y_{t}=\Phi_{1} y_{t-1}+\ldots+\Phi_{p} y_{t-p}+\Gamma x_{t}+\varepsilon_{t}
$$

Donde $\varepsilon_{t}$ es un vector de perturbaciones sin autocorrelación (denominadas innovaciones), con media nula y matriz de covarianzas instantáneas $E\left[\varepsilon_{t} \varepsilon_{t}^{\prime}\right]=\Omega$. Los residuos tienen una matriz de varianzas y covarianzas $\Omega$ que por definición es simétrica y en general no tiene restricciones. Este sistema de ecuaciones es una representación vectorial autorregresiva (VAR $(p)$ ) donde $\varphi_{j}, j=1 \ldots p$ son matrices $\mathrm{nXn}$ que recogen la dependencia de $\mathrm{y}_{\mathrm{t}}$ respecto a $\mathrm{y}_{\mathrm{t}-\mathrm{p}}$. Según la relación (11) $\mathrm{y}_{\mathrm{t}}$ es un vector de k variables endógenas, $\mathrm{x}_{\mathrm{t}}$ es un vector de variables exógenas, $\Phi_{1} \ldots \Phi_{\mathrm{p}} \mathrm{y} \Gamma_{\mathrm{t}}$ son las matrices de coeficientes que van a ser estimadas. Ahora bien, dada la ausencia de simultaneidad en la ecuación, la técnica de mínimos cuadrados ordinarios es la más adecuada para realizar las estimaciones. Para la elección del orden del VAR — es decir, determinar el número de rezagos con los que cuenta - se utiliza el test de razón de verosimilitud, el criterio AIC, entre otros. Y a partir de la estructura del modelo VAR (p) así determinada, se generan las predicciones después de efectuar un diagnóstico general de los modelos estimados. Una vez seleccionado el modelo VAR (p), las respuestas a los problemas económicos planteados se realizan de la siguiente forma: 
Tabla 7

Pruebas de raíz unitaria y de estacionariedad

\begin{tabular}{llllll}
\hline Variables & $\begin{array}{l}\text { Especificación } \\
\text { de la ecuación } \\
\text { de la prueba }\end{array}$ & $\begin{array}{l}\text { Estadística } \\
\text { ADF } \\
\text { Ho: raíz } \\
\text { unitaria }\end{array}$ & $\begin{array}{l}\text { Estadística PP } \\
\text { Ho: raíz } \\
\text { unitaria }\end{array}$ & $\begin{array}{l}\text { Estadística } \\
\text { KPSS } \\
\text { Ho: estaciona- } \\
\text { riedad }\end{array}$ & $\begin{array}{l}\text { Orden de } \\
\text { integración }\end{array}$ \\
\hline Ciclo México & Constante & $-4.315839^{* * *}$ & $-2.967863^{* *}$ & 0.038687 & $\mathrm{I}(0)$ \\
Ciclo USA & Constante & $-3.251191^{* *}$ & $-2.586859^{*}$ & 0.044354 & $\mathrm{I}(0)$ \\
Consumo privado & Constante & $-3.812908^{* * *}$ & $-2.964837^{* *}$ & 0.040275 & $\mathrm{I}(0)$ \\
Inversión privada & Constante & $-3.742488^{* * *}$ & $-3.746117^{* * *}$ & 0.074161 & $\mathrm{I}(0)$ \\
Inversión pública & Constante & $-2.727784^{* *}$ & $-4.103000^{* * *}$ & 0.071142 & $\mathrm{I}(0)$ \\
Gasto público & Constante & $-3.768796^{* * *}$ & $-3.858036^{* * *}$ & 0.056884 & $\mathrm{I}(0)$ \\
Exportaciones & Constante & $-4.247494^{* * *}$ & $-3.388425^{* *}$ & 0.041158 & $\mathrm{I}(0)$ \\
Importaciones & Constante & $-4.346100^{* * *}$ & $-3.316722^{* *}$ & 0.038165 & $\mathrm{I}(0)$ \\
\hline
\end{tabular}

\footnotetext{
* Se rechaza al $10 \%$.

** Se rechaza al $5 \%$.

**** Se rechaza al $10 \%$.
}

el análisis impulso-respuesta o análisis de sensibilidad. De este modo estimamos el modelo VAR (p) estacionario siguiente:

$$
y_{t}=C_{t}+\sum_{j=1}^{p} \Phi_{j} y_{t-j}+\varepsilon_{t}
$$

Donde $\mathrm{y}_{\mathrm{t}}=\left[\mathrm{Q}_{\mathrm{t}}, \mathrm{CP}_{\mathrm{t}}, \mathrm{I}_{\mathrm{t}}, \mathrm{I}_{\mathrm{t}}^{\mathrm{g}}, \mathrm{GDP}_{\mathrm{t}}, \mathrm{GP}_{\mathrm{t}}, \mathrm{M}_{\mathrm{t}}, \mathrm{X}_{\mathrm{t}}\right]$ ' es el vector de variables endógenas estacionarias, $\mathrm{C}_{\mathrm{t}}$ el vector de las constantes y $\varepsilon_{t}$ el vector de la innovaciones del modelo.

\section{Pruebas y resultados}

Como estimamos un modelo VAR (p) estacionario, procedimos a realizar las pruebas de raíz unitaria y estacionariedad para cada una de las 8 variables que vamos a utilizar para construir el modelo VAR (p), y en la tabla 7 presentamos los resultados. Aplicamos una batería de tres pruebas. La primera fue la $\mathrm{ADF}$, cuya hipótesis nula reside en la presencia de raíz unitaria; la segunda prueba es la PP, cuya hipótesis nula es también la presencia de raíz unitaria, y la tercera es la prueba KPSS, cuya hipótesis nula reside en la presencia de estacionariedad, por lo que si se rechaza la hipótesis nula en las dos primeras pruebas, las series son estacionarias, y si no se rechaza la hipótesis nula de la prueba KPSS, se confirma la estacionariedad de las series. Como las variables son estacionarias, no es procedente establecer relaciones de largo plazo entre ellas ni estimar un VEC, por lo que optamos por construir un VAR (p) estacionario, con base en el cual simulamos los efectos de los shocks aleatorios sobre la dinámica del ciclo.

Habiendo corroborado que las 8 variables son estacionarias, procedimos a seleccionar el orden del VAR, para lo cual hicimos uso de 5 criterios de selección del número de rezagos del modelo: 1) el criterio de información de Akaike (AIC); 2) el criterio de Schawz (SC) 1978; 3) el criterio de Hannany Quinn; 4) el cociente de verosimilitud secuencial modificado (LR), y 5) el criterio de error final de predicción (FPE), que se presentan en la tabla 8.

Consideramos que, de acuerdo con el cociente de verosimilitud secuencial modificado (LR) y el criterio de error final de predicción (FPE), el número de rezagos más apropiado es de 2 . Una vez realizadas las pruebas anteriores, estimamos el modelo VAR (2) siguiente, utilizando mínimos 
Tabla 8

Selección de orden de los rezagos

VAR Criterio de selección de orden de número de rezagos

Variables endógenas: ACP AGASTOPUBLICO AINVPRIV AINVPUB AM AMEXICO AUSA AX

Variables exógenas: $\mathrm{C}$

Muestra: 1993Q1 2013Q4

Número de observaciones: 76

\begin{tabular}{lllllll}
\hline Rezago & LogL & LR & FPE & AIC & SC & HQ \\
\hline 0 & 544.4385 & NA & $1.02 \mathrm{e}-16$ & -14.11680 & -13.87146 & -14.01875 \\
1 & 790.5187 & 433.8783 & $8.56 \mathrm{e}-19$ & -18.90839 & $-16.70032^{*}$ & $-18.02594^{*}$ \\
2 & 857.3036 & $103.6924^{*}$ & $8.38 \mathrm{e}-19^{*}$ & -18.98167 & -14.81089 & -17.31483 \\
3 & 908.9146 & 69.26731 & $1.34 \mathrm{e}-18$ & -18.65565 & -12.52214 & -16.20440 \\
4 & 981.8335 & 82.51354 & $1.41 \mathrm{e}-18$ & -18.89036 & -10.79412 & -15.65471 \\
5 & 1050.807 & 63.52837 & $2.11 \mathrm{e}-18$ & -19.02124 & -8.962287 & -15.00120 \\
6 & 1139.706 & 63.16498 & $2.75 \mathrm{e}-18$ & -19.67647 & -7.654798 & -14.87203 \\
7 & 1298.650 & 79.47212 & $1.15 \mathrm{e}-18$ & $-22.17501^{*}$ & -8.190607 & -16.58616 \\
\hline
\end{tabular}

AIC: criterio de información Akaike; FPE: error de predicción final; HQ: criterio de información Hannan-Quinn; LR: secuencial modificado LR prueba estadística (cada prueba a nivel de 5\%); SC: criterio de información Schwarz.

* Indica el orden de rezago seleccionado por el criterio.

cuadrados ordinarios, donde $\Phi_{1} y \Phi_{2}$ son las matrices de los coeficientes, $\mathrm{C}_{\mathrm{t}}$ constituye el vector de las constantes y $\varepsilon_{j t}$ el vector de los errores aleatorios o innovaciones.

$$
\left[\begin{array}{c}
Q_{t} \\
C P_{t} \\
I_{t}^{p} \\
I_{t}^{g} \\
G D P_{t} \\
G P_{t} \\
M_{t} \\
X_{t}
\end{array}\right]=C_{t}+\Phi_{1}\left[\begin{array}{c}
Q_{t-1} \\
C P_{t-1} \\
I_{t-1}^{p} \\
I_{t-1}^{g} \\
G D P_{t-1} \\
G P_{t-1} \\
M_{t-1} \\
X_{t-1}
\end{array}\right]+\Phi_{2}\left[\begin{array}{c}
Q_{t-2} \\
C P_{t-2} \\
I_{t-2}^{p} \\
I_{t-2}^{g} \\
G D P_{t-2} \\
G P_{t-2} \\
M_{t-2} \\
X_{t-2}
\end{array}\right]+\left[\begin{array}{c}
\varepsilon_{1 t} \\
\varepsilon_{2 t} \\
\varepsilon_{3 t} \\
\varepsilon_{4 t} \\
\varepsilon_{5 t} \\
\varepsilon_{6 t} \\
\varepsilon_{7 t} \\
\varepsilon_{8 t}
\end{array}\right]
$$

El sistema VAR (2) estimado cuenta con 81 observaciones para cada una de las ecuaciones, que incluyeron 8 regresores.

\section{Pruebas de estabilidad de los coeficientes}

Para probar la estabilidad del sistema VAR y sus coeficientes se requiere que las raíces inversas del polinomio característico de dicha matriz no salgan del círculo (fig. 3). En este caso, los resultados de las dos pruebas de estabilidad que realizamos demuestran que estas se encuentran al interior del círculo. Para esto realizamos dos pruebas; en la primera se realiza el cálculo de las raíces inversas del polinomio, y de acuerdo con ella las raíces se encuentran al interior del círculo, por lo que el VAR estimado satisface las condiciones de estabilidad, como se observa a 


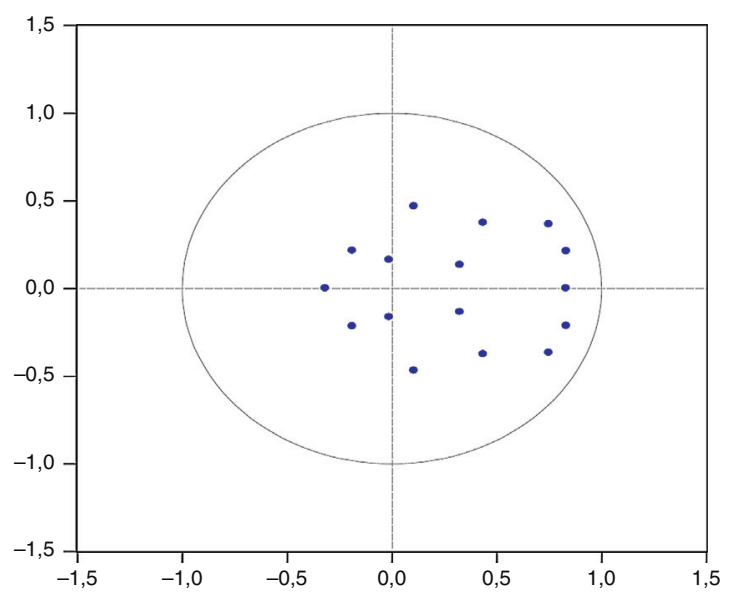

Figura 3. Raíces inversas del AR polinomio característico.

Tabla 9

Pruebas de diagnóstico para los residuales

\begin{tabular}{lll}
\hline Tipo de prueba & Hipótesis nula & Valor de probabilidad \\
\hline Correlación serial $^{\mathrm{a}}$ & Hipótesis nula: no hay correlación serial en el rezago de orden h & 0.3112 \\
Heterocedasticidad $^{\mathrm{b}}$ & Homocedasticidad & 0.5167 \\
Normalidad $^{\mathrm{c}}$ & Normalidad & 0.0000 \\
\hline
\end{tabular}

${ }^{a}$ Prueba de Breusch-Godfrey para los residuales desde el primero hasta el segundo orden.

b Prueba de heterocedasticidad de White para los residuales con rezagos y sin términos cruzados.

c Prueba de normalidad de Jarque-Bera.

continuación: el valor absoluto del módulo disminuye y tiende a cero (véase anexo, tabla 1), y con la segunda prueba se complementan y confirman estos resultados con un análisis gráfico de las raíces.

\section{Pruebas de diagnóstico para los residuales (tabla 9)}

En seguida realizamos una serie de diagnósticos sobre las pruebas de autocorrelación de Breusch-Godfrey sobre los residuos. Estas pruebas son de autocorrelación de orden h. Con base en la prueba, no se rechaza la hipótesis nula de ausencia de correlación serial. tabla 9

De acuerdo con la prueba de heterocedasticidad, no se rechaza la hipótesis nula de ausencia de heterocedasticidad; por otra parte, de acuerdo con la prueba de normalidad encontramos que los residuos no se distribuyen normalmente.

\section{Análisis de sensibilidad}

El siguiente paso consiste en utilizar la técnica desarrollada por Pesaran y Shin (1998) para estimar un conjunto de funciones «generalizadas» de respuesta al impulso (FGRI). Las FGRI tienen la ventaja de no depender del ordenamiento de las ecuaciones del modelo VAR. Estas funciones permiten observar la respuesta «dinámica» de una determinada variable frente a choques o cambios inesperados en alguna otra variable. En la figura 4 se muestra cómo responde el ciclo 

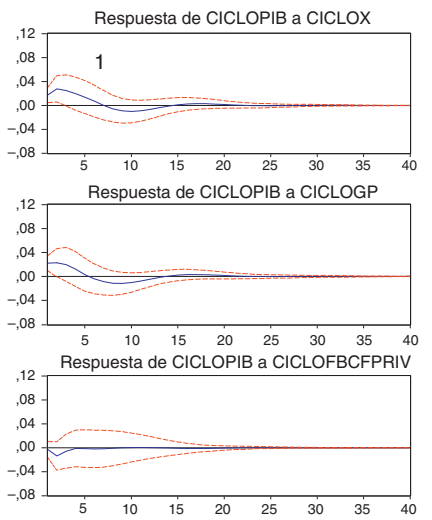
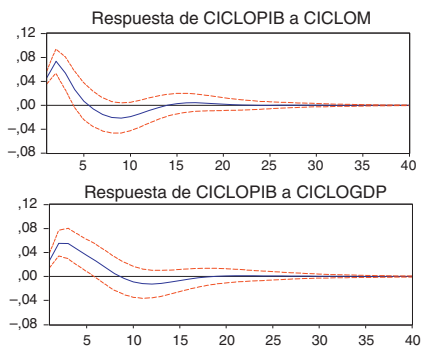

Figura 4. Respuesta a innovaciones, desviaciones estándar generalizadas.

frente a los choques aleatorios provenientes de las variaciones de las exportaciones, el consumo público, las importaciones y el GDP de Estados Unidos, respectivamente. Como puede verse, las FGRI fueron estimadas en horizontes de 40 trimestres e incluyen intervalos de dos desviaciones estándar. Para que una función de respuesta al impulso se considere estadísticamente significativa se requiere que el intervalo excluya al cero en algún punto dentro del horizonte de 40 trimestres. En primer término, lo que se observa es la estabilidad del sistema; esto demuestra la capacidad del sistema para retornar al estado estacionario. La figura 4 muestra que los choques aleatorios derivados de las innovaciones procedentes de las importaciones provocan una expansión del mismo, es decir, tiene una relación procíclica, dado que si aumentan las importaciones aumenta al ciclo, y después de 6 meses el efecto del choque inicial se diluye.

Del mismo modo, los choques aleatorios procedentes de las variaciones del PIB estadounidense inducen a una expansión del ciclo mexicano durante los primeros 10 trimestres, mismo que se diluye después del 11 trimestre. También las importaciones tienen un impacto positivo sobre el ciclo, por lo que tienen un efecto procíclico. La expansión de las exportaciones y el gasto público generan una expansión positiva menos marcada los primeros 2 trimestres y, finalmente, se constata que la inversión no influye sobre el comportamiento del ciclo, con lo cual se deduce que esta variable no ajusta a término el equilibrio del mercado de bienes, como lo plantea el modelo de acelerador-multiplicador.

\section{Pruebas de causalidad de Granger}

Una vez que presentamos los resultados de las funciones generalizadas del modelo VAR y los cambios del ciclo económico mexicano ante choques aleatorios o innovaciones, examinamos la relación de causalidad de tipo Granger entre las variables del modelo VAR, donde X causa en el sentido de Granger a Y, si y solamente si el pronóstico de Y es resultado de los valores pasados tanto de X como de los valores pasados de Y. Granger (1969) distingue entre la causalidad unidireccional y la bidireccional. Se da una causalidad unidireccional de $\mathrm{X}$ a $\mathrm{Y}$, si $\mathrm{X}$ causa a $\mathrm{Y}$ pero $\mathrm{Y}$ no causa a $\mathrm{X}$. Ahora bien, en caso de que ninguna de las variables cause a las otras, se dice que las dos series de tiempo son estadísticamente independientes. En caso de que las variables causen unas a las otras y exista una relación de feedback entre ellas, se dice que existe una relación de causalidad bidireccional entre las mismas Una vez estimado nuestro modelo 
VAR de 8 variables, representado por la ecuación (13), realizamos las pruebas de causalidad de Granger VAR/Bloque Exogeneidad Wald para examinar la relación causal entre las 8 variables del modelo; desde este sistema, una variable endógena puede ser tratada como exógena. Utilizamos los estadísticos Wald con una distribución de tipo chi-cuadrado para probar, en cada ecuación del modelo, la significancia de cada una de las variables endógenas, así como la significancia conjunta de todas las variables endógenas rezagadas. Los resultados se presentan en la tabla 2 del anexo. De acuerdo con el valor de los estadísticos de prueba chi-cuadrado de 32.93 para el ciclo del PIB, se observa que las 8 variables como bloque causan en el sentido de Granger al ciclo con un 0.0029 nivel de significancia, donde únicamente el ciclo estadounidense causa individualmente al ciclo mexicano.

\section{Conclusiones}

1. Las crisis macroeconómicas están vinculadas a los ciclos y surgen cuando la economía pasa de manera súbita de una situación de expansión a una situación de contracción, por lo que se dan en el pico del ciclo (Marx, Hilferding, Schumpeter y Keynes).

2. En el período de análisis identificamos 4 ciclos económicos: la presencia de 3 crisis macroeconómicas importantes ubicadas en los picos, en donde se constata una desaceleración creciente de la economía mexicana derivada de las políticas macroeconómicas de gasto público que han sido procíclicas.

3. Todas estas variables tuvieron un comportamiento procíclico, cuestión extraña sobre todo por el comportamiento del gasto público (consumo público más inversión pública); esto se debe sobre todo a las políticas de estabilización y ajuste macroeconómicas que se han aplicado desde 1988.

4. La sincronización creciente del ciclo mexicano con el norteamericano, que explica la endogenización creciente de las crisis norteamericanas por la economía mexicana, lo cual es el resultado del peso creciente de las importaciones y del GDP norteamericano sobre la economía mexicana (integración económica); además de la creciente importancia del comercio intraindustrial entre ambos países.

5. Las crisis de Estados Unidos, polo dominante de la relación, y los fenómenos económicos derivados de ellas, con todas sus particularidades de desarrollo temporal, técnico y organizador, influyen de manera más contundente sobre la economía mexicana a partir del 2001.

6. De acuerdo con la simulaciones del modelo VAR(2) estacionario, la dinámica de los ciclos la explican principalmente: las importaciones cuya expansiones provocan una reacción positiva del ciclo, los shocks provenientes del GDP (variables externas) y los shocks provenientes del consumo privado (variable doméstica); en menor medida han influido sobre el ciclo las exportaciones y el consumo público. Cabe destacar que los shocks provenientes de la inversión privada no influyen sobre la dinámica del ciclo, lo cual explica la desaceleración creciente de la economía sobre el período. Por demás, todas las variables tienen un comportamiento procíclico y la dinámica de los ciclos está asociada a un patrón macroeconómico propio de una pequeña economía abierta rentista (consumo privado, importaciones y PIB americano). En un país en vías de desarrollo como México, la expansión de la inversión está determinada por la expansión de las importaciones, de ahí el peso de las importaciones en el ciclo económico. Sin embargo, observamos que para el caso de México la inversión privada no causa individualmente al ciclo. 
7. Las variables del sistema en su conjunto causaron en el sentido de Granger al ciclo de la economía mexicana, y en particular el ciclo de los Estados Unidos de América los causó en el sentido de Granger.

\section{Agradecimientos}

Los autores agradecen tanto las observaciones realizadas por el Dr. Víctor Cuevas al presente artículo como aquellas de los dictaminadores anónimos.

\section{Anexo. Material adicional}

Se puede consultar material adicional a este artículo en su versión electrónica disponible en doi:10.1016/j.cya.2016.10.001.

\section{Referencias}

Brito, R. D. y Brianne, B. (2010). Inflation targeting in emerging economies: Panel evidence. Journal of Development Economics, Elsevier, 91(2), 198-210.

Calderón, C., Caire, G. y Sánchez, A. (2012). La estabilización macroeconómica mexicana de 1988-1992, una experiencia heterodoxa. En C. Calderón y V. M. Cuevas (Eds.), Macroeconomía abierta en América Latina: teoría y evidencia. México: EON.

Calderón, C. y Caire, G. (2012). Génesis y desarrollo de la crisis macroeconómica de 1995. En C. Calderón y V. M. Cuevas (Eds.), Macroeconomía abierta en América Latina: teoría y evidencia. México: EON.

Carare, A. y Stone, M. R. (2003). Inflation Targeting Regimes, IMF Working Papers 03/9. International Monetary Fund.

Granger, C. W. J. (1969). Investigating causal relations by econometric models and cross-spectral methods. Econometrica, 37(3), 424-438. http://tyigit.bilkent.edu.tr/metrics2/read/Investigating\%20\%20Causal\%20Relations $\% 20$ by $\% 20$ Econometric\%20Models\%20and\%20Cross-Spectral\%20Methods.pdf

Harrod, R. F. (1948). Towards a Dynamic Economics. London: Mac Millan.

Hilferding, R. (1971). El capital financiero. Cuba: Editorial de Ciencias Sociales, Instituto Cubano del Libro.

Juglar, C. (1889). Des crises commerciales et leur retour périodique en France, en Angleterre et aux États-Unis (2ème édition). Paris: Guillaumin.

Kalecki, M. (1935). A macrodynamic theory of business cycles. Econometrica, 3(3). https://archive.org/ details/Kalecki1935.AMacrodynamicTheoryOfBusinessCycles

Keynes, J. M. (2005). Théorie générale de lémploi, de l'intérêt et de la monnaie. Paris: Éditions Payot \& Rivage.

Marx, K. (1965). Euvres économie I y II. Paris: Éditions Gallimard.

Pesaran, M. y Shin, Y. (1998). Generalized Impulse Response Analysis in Linear Multivariate Models. Economics Letters, $58,17-29$.

Samuelson, P. A. (1938). Interactions between the multiplier analysis and the principle of acceleration. Review of Economics Statistics, (21).

Schumpeter, J. (1935). Théorie de lévolution économique. Paris: Librairie Dalloz. 